\title{
EL DEBATE PARLAMENTARIO \\ DE LOS PRESUPUESTOS GENERALES DEL ESTADO ${ }^{1}$ \\ POR \\ EMILIO RECODER DE CASSO \\ Letrado de las Cortes Generales
}

A cualquier estudioso que se enfrenta con el tema de las conexiones entre presupuestos y Parlamento, y más todavía si es espectador de primera fila e incluso un poco protagonista, le alcanza un sentimiento de perplejidad grande. Por un lado, se resalta la importancia y trascendencia del debate presupuestario, su rango de momento solemne en la vida del Estado; por otro, en cambio, desde el debate mismo se proyecta una sensación de tedio, desencanto e incluso de frustración, sin duda producida por la diferencia que se advierte entre lo concebido y lo que la realidad permite.

Este contraste, que no es imaginario, sino vivo y sentido, suele explicarse invocando la complejidad técnica de una ley que, si bien incluye opciones típicamente políticas, sólo es completamente manejable y comprensible tras años de especialización.

Aun sin ser inexacta esta explicación, es, no obstante, insuficiente por sí misma para dar cuenta del fenómeno apuntado. Si se profundiza un poco más, nos damos cuenta de que aquel contraste es una manifestación, y muy rica, de las relaciones que legislativo y ejecutivo mantienen en la fase histórica del Estado en que nos encontramos en las sociedades occidentales, conocida con el nombre de Estado social de Derecho.

El artículo 1..$^{\circ}$ de la Constitución dice que «España se constituye en un Estado social y democrático de Derecho».

No está de más por eso iniciar esta exposición recordando los contenidos esenciales de esa modalidad del Estado.

Es una formulación debida al tratadista de teoría política y del Estado Hermann Heller, quien, enfrentado con el problema de la crisis de la democracia y del Estado de Derecho en los años veinte y treinta de este siglo, piensa que la solución está en dar al último un contenido económico y social, realizar dentro de su marco un nuevo orden laboral y de distribución de bienes

${ }^{1}$ Conferencia pronunciada el día 28 de junio en el Instituto de Estudios Fiscales. 
La idea del Estado social fue institucionalizada por vez primera en 1949 por la Ley Fundamental de Bonn, cuyo artículo 20 define a la República Federal Alemana como «un Estado federal, democrático y social», confirmándola en el artículo 28 como «un Estado democrático y social de Derecho». Los caracteres o rasgos de esta fórmula son magníficamente expuestos por García Pelayo en su libro sobre Las transformaciones del Estado contemporáneo:

- El Estado social significa históricamente el intento de adaptación del Estado tradicional -Estado liberal burgués- a las condiciones sociales de la civilización industrial y postindustrial.

- Se tiende a una política de dirección permanente y programada del conjunto, aunque no de los detalles, del sistema económico global.

- Nos encontramos con una tendencia a la estatización de la sociedad, pero también con una tendencia a la socialización del Estado y, por tanto, a la difuminación de límites entre ambos términos.

- El Estado social ha sido designado por Forsthoff como el Estado que se responsabiliza por la «procura existencial», o sea, por llevar a cabo las medidas que aseguren al hombre las posibilidades de existencia que no puede asegurarse por sí mismo. Debe, no obstante, advierte E. R. Huber, evitarse que la libertad del individuo quede anulada mediante un sistema perfecto de protección estatal.

- El Estado de nuestro tiempo se ha convertido en empresario, llevado a ello por motivaciones de índole varia; lo que caracteriza cualitativamente al Estado social no es, sin embargo, una política de nacionalización de los medios de producción, sino una más justa distribución de lo producido, llevada a cabo por la adecuada utilización para tal fin de la tradicional potestad fiscal.

- Unido a lo anterior, asistimos a la transformación de un Estado predominantemente legislativo en un Estado predominantemente administrativo o de prestaciones o en un Estado manager de la sociedad nacional, asociado a un principio de legitimidad o eficacia de su gestión, principio que coexiste con otros principios de legitimidad y que en el sistema del Estado social debe interactuar con la legitimidad democrática.

- El Estado social es un Estado de asociaciones (Verbandestaat), es decir, un Estado en cuyas decisiones toman parte en una medida decisiva no solamente los partidos, sino también las grandes organizaciones $\mathrm{o}$ asociaciones que, a su vez, pueden influir en los partidos o ser influidas por éstos. La razón para esto se halla en que el Estado social distribuidor tiene como substratum al «hombre situado», en expresión utilizada por Burdeau para contraponerlo al citoyen abstracto y uniforme. De modo que la política se convierte en una buena parte en un conflicto de intereses que busca en el Estado no tanto normas generales cuanto acciones que afecten a intereses concretos, que los individuos han de defender por mediación de organizaciones.

- Siendo la función capital del Estado, ante todo, actuar, el locus de la decisión se traslada a las instancias que por su estructura están en capacidad de actuar, y concretamente del Parlamento, a las instancias gubernamentales y administrativas, con la excusa de que los parlamentos, lentos y sin especialización, no están en condiciones de administrar. 
Sobre estos ejes, es posible comprender con más exactitud el alcance del debate de los presupuestos, habida cuenta que las limitaciones que el Parlamento experimenta en esa tarea son una natural consecuencia de la posición que le ha tocado jugar en esta nueva fase por la que atraviesa el Estado. Para un marxismo crítico, no obstante, la debilitación del Parlamento aparece ligada a las nuevas circunstancias del capitalismo monopolístico, y sus funciones son primordialmente las de reproducción de las relaciones de producción monopolística y de regulación en forma interesada de las crisis del sistema, funciones cuyo ejercicio precisa de una forma de dominación política que no es posible desarrollar en los parlamentos por dos razones principales: por un lado, por la distancia que separa a la fracción burguesa monopolística de las fracciones no monopolísticas, distancia que las convierte en inconciliables; por otro, por la oposición que encuentra en los parlamentos debido a la penetración de los partidos de clase dominada y a la crisis de los partidos de clase dominante.

De ahí que, según esta tesis, en la que participan, por ejemplo, Poulantzas, H. Lefèbvre y Gluksman, la fracción monopolística abandone el Parlamento y se sitúe en el ejecutivo. Lo que explicaría el predominio de éste, no por los motivos técnicos, como quieren dar a entender los teóricos del Estado social de Derecho, sino por motivos estrictamente políticos.

Sea cual sea la interpretación ideológica, lo cierto es que en los presupuestos del Estado, en las relaciones que en torno a ellos mantienen Gobierno y Parlamento, se refleja mejor que en ningún otro documento la nueva dimensión asumida por el Estado desde la perspectiva de la acción. Se ha vuelto práctica usual en el ciclo presupuestario adjudicar al Gobierno la preparación y la ejecución, dejando al Parlamento la aprobación y el control. Es evidente por sí, y no necesita demostración que quien prepara y ejecuta tiene más poder efectivo que quien aprueba y controla.

Centrémonos ya en la segunda fase del ciclo: la aprobación.

Sabido es que las funciones que sobre materias financieras desarrollaron los parlamentarios medievales no sólo les permitieron pervivir a lo largo de varios siglos, sino también convertirse en órganos de fiscalización y control de la política a realizar. Esta última conquista era demasiado importante para pasar desapercibida cuando con la Revolución francesa ocurre la revisión de las estructuras existentes hasta el momento, y es así como en la propia Declaración de Derechos del Hombre y del Ciudadano de 1789 se consagra tanto el principio por el cual «no hay tributación sin representación» como el carácter fiscalizador y de control del Parlamento sobre las materias financieras. «Todos los ciudadanos tienen el derecho de constatar por ellos mismos o por sus representantes, la necesidad de la contribución pública, de consentirla libremente, seguir su aplicación, determinar su cantidad y cualidad, la manera de cubrirla y su duración (art. 14).

En los años siguientes todos y cada uno de los Estados van acogiendo y aumentando esta competencia parlamentaria, de suerte que hoy día el Cuerpo Legislativo posee una serie de facultades que van más allá de lo consagrado en la Declaración de Derechos del Hombre y del Ciudadano.

El actual Parlamento, en efecto, ya no se contenta con la determinación 
de tributos concretos mediante la emisión de leyes impositivas de carácter permanente y el examen y aprobación anual del presupuesto, sino que legisla, mediante leyes de programa, sobre planes económicos de conjunto llamados a cubrir uno o más años.

Aquí se impone una precisión. Se ha hablado de leyes impositivas de carácter permanente, por un lado; y de ley de aprobación del presupuesto, por otro. Esto, sin embargo, no ha sido siempre así, y no es siempre así hoy día. La llamada por $\mathrm{O}$. Mayer «bifurcación del principio de legalidad financiera» es tardía. Mientras no existió un sistema permanente de ingresos, explica Sảinz de Bujanda, los gastos públicos se cubrían en su mayor parte con las rentas del patrimonio de la Corona. Pero a veces, para afrontar necesidades extraordinarias (por ejemplo, guerras), el rey se veía precisado a acudir a los súbditos para pedir autorización para establecer y recaudar determinados tributos por un período más o menos largo, pero siempre limitado. Los representantes del pueblo (Cortes, Parlamento) concedían los recursos necesarios a la Corona, «consintiendo» la recaudación de los tributos o ayudas que el rey habia solicitado, pero reservándose el derecho de juzgar sobre la necesidad y conveniencias de la petición, así como del empleo que había de darse a las cantidades concedidas. Otto Hintze considera, en su importante artículo sobre «las condiciones histórico-universales de la Constitución representativa», a esta práctica como condicionante del desarrollo de la Constitución estamental, sucesora en el Occidente europeo del feudalismo y precursora del moderno Estado representativo. De acuerdo con aquélla surgió el principio de que no podían exigirse tributos cuya recaudación no estuviese prevista y autorizada por la Ley de Pre. supuesto. Ahora bien, la transformación de las funciones del Estado - con la consiguiente expansión del gasto público- hizo necesario organizar en muchos países un sistema permanente de impuestos, y se produjo entonces la citada bifurcación del principio de legalidad financiera, separándose el principio de legalidad de los tributos del principio de legalidad presupuestaria. Desde este momento el establecimiento y exacción de los tributos encontró su fundamento jurídico no ya en la Ley de Presupuestos, sino en las leyes tributarias particulares, y el presupuesto dejó de constituir una limitación jurídica en materia de ingresos, puesto que la Administración puede recaudar todas las cantidades que resulten de la aplicación de las normas tributarias, independientemente de las cifras consignadas en aquél.

La precisión no es gratuita, porque existen ordenamientos jurídicos que conservan la memoria de su origen en los que todavía rige la regla de la anualidad del impuesto (como Bélgica, Méjico y Luxemburgo). La ley presupuestaria constituye en ellos «un acto condición» (según la clasificación lanzada por la escuela realista del Derecho: Duguit e Ieze) que cumple la función de integración de las leyes tributarias existentes (leyes imperfectas) haciendo posible la aplicación de las mismas. En los ordenamientos en que se ha producido la transformación expuesta, la ley presupuestaria tiene en cambio en materia de ingresos el carácter de una mera previsión. En todo caso, con uno u otro contenido la aprobación del presupuesto es uno de los cometidos del Parlamento.

Ante todo, preguntémonos qué alcance tiene la aprobación. No nos referimos - todavía - al conocido problema de la naturaleza jurídica de la Ley de 
Presupuestos, sobre el que más adelante habrá ocasión de hablar, sino que más bien nos interesa ahora situar la actuación del Parlamento dentro de las funciones del Estado. Loewenstein, al estudiar el inevitable tema de la separación de los poderes, aporta una nueva distribución entre policy determination, policy execution y policy control, que, a su juicio, se aproxima más a la realidad política. Pues bien, la actividad del Parlamento al aprobar los presupuestos se ha situado por los distintos autores o en la primera o en la última de las categorías de Loewenstein, aunque también existen, como veremos, los escépticos.

$\mathrm{El}$ encaje en la policy determination es habitual entre los italianos, quienes acostumbran a utilizar el término, acuñado en 1939 por Enzo Crisafulli, de indirizzo politico. La actividad así calificada es la que determina en cada momento los fines hacia cuya consecución tienden armónicamente las demás actividades estatales; es la predeterminación de los fines últimos y más generales y de las posiciones concretas de la acción estatal por obra del órgano o de los órganos competentes.

Pues bien, del presupuesto se ha dicho por Mortati, Rogari, Buscenza y Tossi, entre otros, que es un acto de indirizzo por el que el Parlamento manifiesta un acuerdo global con las grandes opciones de la política gubernamental.

La doctrina francesa suele en cambio tratar al presupuesto, dentro de la policy control, como el arma más importante que el Parlamento tiene para someter a reexamen la acción del Gobierno, aunque la presencia vigorosa de los grupos de presión, la crisis de la representación en el Parlamento, el sistema de partidos y la disciplina de los grupos parlamentarios, junto con la unidad de dirección entre Gobierno y mayoría hacen hoy escasamente atendible la teoría del control.

Entre los escépticos tenemos a Manzella en Italia y a Lalumière en Francia.

Manzella opina que la aprobación del presupuesto constituye para el Parlamento más bien un gesto político formal que una verdadera y propia decisión de indirizzo.

Lalumière, por su parte, en esta misma línea pesimista, considera que el Parlamento no tiene posibilidades reales de elección. El Gobierno presenta como un acto de confianza lo que no es en realidad sino un acto de resignación. El presupuesto tiende a reducirse a un simple documento técnico-burocrático, preparado y aprobado en función exclusiva de las demandas de los servicios gubernamentales. Instrumento interno de trabajo de las administraciones, tiene la autoridad que éstas tienen a bien reconocerle, y ésta no es otra, como la experiencia demuestra, que la de un trozo de papel que en el curso del año es modificado profundamente en función de la relación de fuerzas en el seno del aparato del Estado.

Entrando ya en el procedimiento, destacaremos que hay muchos países en los que la discusión y aprobación de la ley presupuestaria se realiza en forma idéntica a la ley ordinaria (así en Argentina, Bélgica, Italia, Méjico, etc.), pero hay otros, y especialmente los de influencia británica, donde se sigue un procedimiento diferente, que puede consistir en el establecimiento de plazos breves para la discusión, en el requerimiento de una mayoría especial para su aprobación o en la exclusión total del Senado en las fases de discusión y aprobación. 
A) La elaboración de los Presupuestos Generales del Estado corresponde al Gobierno, de acuerdo con el artículo 134.1 de la Constitución. Ya hemos dicho que es lo habitual en todos los países, y el proceso seguido en USA, suficientemente divulgado ya - lo que nos excusa su repetición-, es muy ilustrativo.

«El Gobierno debe presentar ante el Congreso de los Diputados los presupuestos al menos tres meses antes de la expiración de los del año anterior», dice el artículo 134.3 de la Constitución. Por razones evidentes, derivadas de su temporalidad, el proyecto de Ley de Presupuestos goza de preferencia en la tramitación sobre los demás trabajos de la Cámara. Así lo disponen los regla. mentos. La mesa del Congreso puede controlar los requisitos formales del proyecto, o sea, cuidar que esté acompañado de todos los documentos exigidos por las leyes de procedimiento administrativo y general presupuestaria, y negarse a admitir el proyecto si no se halla completo. Pero una vez admitido y ordenada su publicación, cualquier defecto de forma que más adelante se advierta no puede ser obstáculo a la tramitación, sin perjuicio, por supuesto, de que se solicite lo que se considere pertinente.

B) En este punto debe mencionarse una cuestión original: es la que atañe al llamado Fondo de Compensación, regulado por el artículo 158.2. Dice este precepto lo siguiente:

«Con el fin de corregir desequilibrios económicos interterritoriales y hacer efectivo el principio de solidaridad, se constituirá un Fondo de Compensación con destino a gastos de inversión, cuyos recursos serán distribuidos por las Cortes Generales entre las comunidades autónomas y provinciales, en su caso.»

Razonablemente, la consignación para el Fondo de Compensación deberá figurar en la Ley de Presupuestos, si se entiende que la dotación de aquél corre a cargo del Estado. Pero para su distribución la Constitución esboza un método diferente del habitual de cualquier proyecto de ley. En el artículo 74.2 se dice que «las decisiones de las Cortes Generales, previstas en los artículos 94.1, 145.2 y 158.2, es adoptarán por mayoría de cada una de las cámaras. En el primer caso, el procedimiento se iniciará por el Congreso, y en los otros dos por el Senado. En ambos casos, si no hubiera acuerdo entre Senado y Congreso, se intentará obtener por una comisión mixta compuesta de igual número de diputados y senadores. La comisión presentará un texto que será votado por ambas cámaras. Si no se aprueba en la forma establecida, decidirá el Congreso por mayoría absoluta».

La distribución del Fondo de Compensación del artículo 158.2 ha de ser, pues, objeto de una «decisión de las Cortes Generales», cuyo procedimiento «se iniciará por el Senado». La palabra «decisión» parece eliminar la necesidad de que la distribución se haga por medio de una ley. Los otros dos supuestos a los que se aplica son la autorización que las Cortes Generales presten para la ratificación de determinadas categorías de tratados, y las que asimismo les toca prestar para que entre comunidades autónomas puedan celebrarse acuerdos de 
cooperación no previstos en los estatutos. En los tres casos la Constitución evita hablar de ley, y sin embargo no se comprende bien cómo puede expresarse la voluntad vinculante de las Cortes Generales bajo una forma que no sea la de ley.

Así, pues, nuestra opinión es que la distribución del Fondo de Compensación debe hacerse por medio de una ley. Además, pensamos que la iniciativa debe corresponder al Gobierno, que es quien está en mejores condiciones para conocer el grado de desequilibrio existente entre territorios y el ritmo que es necesario o conveniente llevar hasta conseguir el equilibrio buscado, aparte de que la nivelación de las comunidades autónomas y provincias, en su caso, debe ser un aspecto de la política global del Gobierno.

Este punto sentado, hay que preguntarse si la propuesta deberá incorporarse a la Ley de Presupuestos o podrá ser objeto de una ley independiente. Aunque sólo sea por razones de procedimiento, esto último parece lo más razonable, ya que, si fuera en el mismo proyecto que los presupuestos, la aprobación de estos últimos sufriría una demora innecesaria; el Congreso de los Diputados estaría impedido de conocer la distribución del Fondo de Compensación hasta que el Senado se pronunciara.

El lugar de presentación del proyecto de ley de distribución debe ser, lógicamente, el Senado, aunque en principio eso va contra lo dispuesto por el artículo 88 de la Constitución, a cuyo tenor «los proyectos de ley los someterá el Consejo de Ministros al Congreso»; ahora bien, parece que cuando la propia Constitución establece una excepción en el procedimiento y dice que éste se iniciará en el Senado hay que llevarla a sus consecuencias más directas, entre las que se cuenta la de que el procedimiento se inicia con la presentación del proyecto. También podría defenderse que, presentado el proyecto de ley de distribución en el Congreso, de acuerdo con la norma general del artículo 88, esta Cámara debe, cumpliendo el artículo 74.2, dar traslado del mismo al Senado. Sin embargo, esta solución nos parece atentatoria, en cierto modo, a la dignidad constitucional del Senado.

C) Organo de deliberación. Cuando funcionan comisiones permanentes especializadas («concepción continental» o «americana» opuesta a la «concepción británica» sobre el papel de las comisiones), ocupa un lugar preponderante la comisión encargada de los asuntos financieros y presupuestarios. Su competencia no siempre es exclusiva en materia de presupuesto, sino que, dadas las repercusiones del mismo en todos los ámbitos de actividad pública, puede ser conveniente consultar a otras comisiones directamente implicadas por la afectación y reparto de los créditos. Pero, en todo caso, la Comisión de Presupuestos conserva una posición preponderante.

Veamos lo que ocurre en algunos países:

- En Francia y Noruega, las demás comisiones «técnicas» pueden solicitar ser oídas sobre los problemas de su competencia y pueden publicar sus observaciones en informes separados.

- En Alemania Federal, el Reglamento del Bundestag no prevé nada parecido, pero si hay alguna comisión interesada que desea opinar puede hacerlo 
por escrito dirigido a la Comisión de Presupuestos. Esta última, en su caso, recogería la opinión en su propio dictamen.

- En Italia y en Bélgica, la Comisión de Presupuestos juega un papel más borroso, porque cada una de las restantes comisiones es competente para examinar, en primer término, los estados de previsión para aquellos sectores que son de su competencia. Cada comisión elabora un dictamen de la parte que le toca, y nombra un ponente que se encargará de informar a la Comisión de Presupuestos. A ésta corresponde confeccionar el dictamen.

Silvano Tossi en su Diritto Parlamentare comenta favorablemente la regulación italiana, por entender que hace posible un examen profundo del presupuesto, habida cuenta de que las comisiones permanentes representan la sede ideal para un examen general, y al propio tiempo especializado, de la política de cada rama de la Administración.

En España seguimos el sistema de atribuir a una comisión especializada la plenitud de competencia para el estudio de los presupuestos. De su seno se forma una ponencia con la misión de elaborar un informe sobre las enmiendas presentadas. Lo suyo sería que este órgano se atuviera a una consideración desapasionada de las enmiendas y que su informe versara sobre la significación que cada una de ellas tiene en relación con el proyecto y con el resto del ordenamiento vigente. Pero el Patbos político, cuyo ámbito propio es la comisión en cuanto a la negociación, y el pleno en cuanto a la divulgación, se ha precipitado, y está haciéndose sentir ya en la fase de ponencia, de manera que puede decirse que en general no hay ningún momento en que pueda hacerse una valoración fría y técnica de los proyectos de leyes. El resultado es que las ponencias se han erigido en comisiones reducidas en las que todos los grupos participan con voto ponderado, constituyendo el terreno de la negociación y convirtiendo en innecesaria la fase de comisión.

En gran medida eso ha sido debido a la publicidad que, según los reglamentos de las cámaras, tienen las sesiones de comisión, a las que la prensa asiste normalmente, lo que hacía indispensable buscar un medio apto para negociar, que se ha encontrado en la ponencia.

Esperemos que en los nuevos reglamentos se rodee al debate en comisión de la reserva que toda negociación precisa. Las ponencias podrán entonces adquirir la serenidad, que resulta imprescindible para un estudio técnico de los problemas, sin cuya base difícilmente puede existir una buena política.

D) La intervención del Senado. El papel desempeñado por el Senado en materia presupuestaria tiene diversas modalidades:

a) Primacía de la Cámara Baja sobre el Senado. El papel del Senado en los países que siguen el modelo inglés se encuentra notablemente disminuido. En Australia, Canadá, India, Irlanda y Sudáfrica, por ejemplo, el Senado no sólo tiene reducido el plazo para considerar el proyecto enviado por la otra Cámara - por lo que si no lo aprueba dentro del lapso se considera como ley sancionada por el Parlamento-, sino que, además, las enmiendas que sugiera no son vinculantes para la otra asamblea, dejándose a su criterio el acogerlas o rechazarlas. 
En otros casos, si bien es cierto que el Senado tiene un plazo menor que la Cámara Baja para decidir sobre el proyecto presupuestario, puede enmendarlo, y los posibles conflictos que surjan por falta de acuerdo deberán ser resueltos según los procedimientos existentes en materia de legislación ordinaria (Francia y Japón).

b) Igualdad entre ambas Cámaras en lo referente a procedimiento: cada Cámara puede deliberar durante el tiempo que estime necesario, así como enmendar lo resuelto por la otra (Italia, Bélgica, Suiza y República Federal Alemana).

c) Exclusión total del Senado: así ocurre en Gran Bretaña, donde a la Cámara de los Lores la está vedado inclusive dar una recomendación, correspondiendo íntegramente a la Cámara Baja la discusión y aprobación; en Méjico la exclusividad en materia de aprobación de gastos corresponde a la Cámara de Diputados, pero no así en lo que se refiere a los ingresos.

En España no hay ninguna peculiaridad que ataña al Senado en materia presupuestaria. El artículo 134.1 dice que corresponde a las Cortes Generales el examen, enmienda y aprobación de los Presupuestos Generales del Estado, y a esta actividad aplícase el artículo 90 de la Constitución en cuanto a la intervención del Congreso y del Senado en la aprobación de las leyes. Es decir, que en principio el Senado tiene un plazo de dos meses para deliberar sobre el texto que le remita el Congreso e introducir enmiendas en él, y al Congreso corresponde decir la última palabra.

Según el artículo 90 citado, el Senado puede también oponer su veto por mayoría absoluta. Tras esa posibilidad de vetar el presupuesto late un problema de gran calibre, toda vez que siendo el presupuesto el instrumento fundamental de la acción del Gobierno cabe preguntarse hasta qué punto el veto al presupuesto no significa una censura al Gobierno de tal envergadura que sea por lo menos lícito dudar si el Senado tiene capacidad para formularlo, dado que, en efecto, según la Constitución, artículo 113, sólo el Congreso puede exigir la responsabilidad política del Gobierno a través de la moción de censura. Es cierto que el veto puede ser enervado por mayoría absoluta en el Congreso, pero, ¿cómo podría el Gobierno mantenerse con la hostilidad abierta de una de las Cámaras?

Es, bien lo sabemos, muy improbable que eso llegue a ocurrir mientras el Gobierno tenga mayoría en las dos Cámaras, pero puede muy bien suceder un día que la relación de fuerzas en las Cámaras sea tan diferente que la oposición domine en el Senado. Teniendo en cuenta, además, que esta Cámara se siente tan legitimada democráticamente coom el Congreso, al proceder sus miembros del sufragio universal, no habría que extrañarse que aproveche cualquier carta a su alcance, la interpretación más favorable, para reforzar sus competencias.

Consideramos, sin embargo, que jugar la carta del veto al presupuesto como sucedáneo de la moción de censura equivale a incurrir en fraude de Constitución, pues con ello se vulnera todo el procedimiento del artículo 113, y en especial la exclusiva que el artículo otorga al Congreso para exigir responsabilidad política al Gobierno.

Estamos ahora en un momento en el que cualquier solución es posible, pues se está estudiando el Reglamento del Senado. Nuestra postura ante el 
tema es que en la regulación del procedimiento presupuestario ante el Senado sólo debiera permitirse la introducción de enmiendas, aunque somos conscientes de que es muy difícil que esta tesis sea recogida por un Senado naciente que se encuentra, además, con atribuciones injustamente - dada la forma de elección de sus miembros- limitadas en el terreno legislativo.

Sin pretensión profética alguna, creemos que si el Senado va a poder oponer su veto a los Presupuestos Generales del Estado, antes o después tocará al Tribunal Constitucional emitir su veredicto en virtud de recurso, presentado por el presidente del Gobierno de turno.

E) Las enmiendas. En relación con las enmiendas a la ley presupuestaria, hay que tratar una cuestión previa. ¿Es verdaderamente enmendable? La pregunta puede parecer retórica, pero no es así, pues una respuesta afirmativa puede estar en relación con la posición que se sustente respecto al polémico problema de la naturaleza jurídica de la Ley de Presupuestos. Nada menos.

Sabido es que ese tema nace en la Alemania de Bismarck, a fines del siglo xIx; allí razones ideológico-políticas e ideológico-científicas, como demostró Herman Heller en su denuncia ante la Asociación Alemana de Profesores de Derecho Público en 1927, dieron origen, de la mano de Gneist y Laband, a la distinción entre ley material y ley formal. La primera puede crear reglas jurídicas, mientras que la segunda no tiene de la ley más que la forma solemne que la cubre, pero no puede innovar el ordenamiento, sino que debe respetar la regulación existente. Lo que se pretendía con la distinción, en la circunstancia específica en que nace, es bien conocido: evitar que el Parlamento prusiano se negara a aprobar el presupuesto con el argumento de:

- Que el presupuesto era una ley en sentido formal.

- Que la competencia del poder legislativo consistía únicamente en la emanación de leyes en sentido material, y

- Que, consiguientemente, no correspondía al legislativo, sino que eta atribución del ejecutivo dictar disposiciones relativas a la organización del Estado, y en particular la confección de los Presupuestos del Estado.

Heller arguyó que esto no era más que una argucia de una sociedad que se sentía segura y feliz mientras sus intereses privados se encontraran protegidos por la ley, pero que era al propio tiempo incapaz de resistir al poder político y al Estado.

Sea lo que fuere de esto, lo cierto es que la escuela francesa de Duguit mantuvo, con argumentos diferentes, el carácter meramente formal de la Ley de Presupuestos, y a partir de ese momento se entabló una polémica, sin cerrar todavía, entre los partidarios de considerar a la LP como ley formal o como ley material, y con capacidad, por consiguiente, innovadora del ordenamiento jurídico. Rogari, en su obra sobre Il bilancio dello stato, entiende que en los países de la CEE predomina la tesis formalista.

Pensemos ahora en la repercusión que esta polémica tiene en la tramitación parlamentaria de los presupuestos y, más concretamente, en la facultad de enmendar. 
Si el presupuesto es simplemente un documento administratitvo que cuantifica las obligaciones que el Estado debe asumir, porque así lo imponen las leyes materiales en vigor, está claro que el Parlamento no debe poder enmendar, pues su única misión es autorizar al Gobierno el ejercicio de poderes conferidos ya por otras leyes.

No es un problema teórico, sino que en Italia la doctrina ha tenido que plantearse esta cuestión a partir del artículo 81.3 de su Constitución, que prohíbe la introducción de nuevos tributos o de nuevos gastos con la ley de aprobación del presupuesto. Ha desechado, pese a todo, la objeción que a la facultad de enmienda se levanta desde el carácter formal que allí tiene la LP en base a variados argumentos:

a) Sin posibilidad de enmendar, el debate será puramente teórico.

b) La facultad de enmienda se deriva, ante todo, de la titularidad de la función legislativa, confiada por la Constitución al Parlamento, que es función a la que debe reconducirse también la aprobación de las leyes formales y que comprende, naturalmente, el ejercicio del poder de enmienda.

c) Si se conviene además, dice Tossi, que el acto de autorización parlamentaria es un acto de indirizzo, o sea, un acto político del Parlamento, la plena legitimidad de las enmiendas resulta cabalmente de la naturaleza negocial que los actos de ese género tienen en un régimen parlamentario.

Entre nosotros la cuestión está muy clata a partir de la letra del artículo 134.1 de la Constitución, que atribuye a las Cortes Generales el examen, enmienda y aprobación de los Presupuestos Generales del Estado.

Las limitaciones proceden de otros campos. Son sobradamente conocidas, por lo que puede ser inoportuno reiterar su procedencia, pese o lo cual no nos resistimos a citar algunas, reveladoras todas ellas de la originalidad del procedimiento presupuestario. En primer lugar, la exigencia de requisitos especiales a las enmiendas al Proyecto de Ley de Presupuestos, como el mayor número de firmas o la necesidad de lo que se ha llamado una «formulación constructiva» para las enmiendas que propongan aumento de gasto, que se traduce en la obligación de señalar en la propia enmienda los ingresos nuevos con los que financiar el mayor gasto o la partida del presupuesto, donde se va a producir una rebaja compensadora. Con esta exigencia se trata de evitar tanto la demagogia del gasto, a la que con miras electoralistas se pueden ver tentados los parlamentarios, como la ruptura del equilibrio que el Gobierno ha querido imprimir a su política económica; pero con ella se pretende asimismo, como recuerdan Trotabas y Cotteret, mantener la filosofía originaria del presupuesto, como autorización que el Parlamento presta al gasto pedido por el Gobierno. La misión del Parlamento consistía, en efecto, en limitar al mínimo estricto los créditos pedidos $\mathrm{y}$, consiguientemente, los impuestos con que subvenirles. $\mathrm{Y}$ así, el Parlamento británico, forjador primero junto a las Cortes de Castilla y heredero después de esa tradición, conoce la prohibición, expresa desde 1713, de que la Cámara de los Comunes ejerza iniciativa alguna que suponga aumentar así el gasto como el ingreso.

La peculiaridad de la enmienda presupuestaria a la que venimos refiriéndonos aparece en nuestro ordenamiento vigente en los reglamentos provisionales del Congreso de los Diputados y del Senado en los siguientes términos: 
«Las enmiendas al Proyecto de Ley de Presupuestos que supongan aumento de crédito en algún concepto únicamente podrán ser admitidas a trámite si, además de cumplir los requisitos generales, en la propia enmienda se propone una baja de igual cuantía en otro concepto de la misma sección.»

Con esta redacción se asegura la intangibilidad del proyecto en los totales consignados en cada sección y se impide, por tanto, el traspaso de créditos entre secciones.

En la práctica, la adaptación a esa formulación se ha revelado difícil, pues exige un estudio a fondo de las diferentes partidas de la sección que se quiere enmendar. Ello ha motivado, por ejemplo, que de las aproximadamente 360 enmiendas presentadas al Proyecto de Ley de Presupuestos del presente ejercicio 51 tuvieran que ser rechazadas de plano por no incorporar una formulación «constructiva» o por pretender una compensación con créditos de una sección diferente de aquélla cuyo crédito quería aumentarse, o incluso con el presupuesto de algún órgano autónomo.

Creo que conviene resaltar que esta limitación de la iniciativa parlamentaria resulta directamente de los reglamentos de las Cámaras $\mathrm{y}$, por consiguiente, de una autolimitación de estas últimas, a la que no vienen obligadas por la Constitución. En ésta, en efecto, se dice lisa y llanamente que a las Cortes Generales corresponde la enmienda de los Presupuestos Generales del Estado, y no se le pone a ese poder cortapisa alguna. Para nosotros, esto es evidente, según la Constitución, nada se opone a que el Parlamento enmiende el presupuesto en el sentido de aumentar el gasto previsto en el proyecto enviado por el Gobierno.

Podría objetarse que el propio artículo 134 dice, en el apartado 6, que «toda proposición o enmienda que proponga aumento de los créditos o disminución de los ingresos presupuestarios requerirá la conformidad del Grobierno para su tramitación; sin embargo, este precepto no es aplicable al debate de los Presupuestos Generales del Estado, sino a épocas posteriores. Varias consideraciones abonan esta tesis:

Primera. Hay una ilación directa del mentado apartado 6 con el anterior, hasta el punto de que formaban un solo apartado en el texto salido del Congreso; la escisión en el Senado fue aprobada en virtud de una enmienda in voce, y sin otra justificación que la de aligerar un contenido que se consideraba denso en exceso para un solo apartado. El texto era el siguiente: «Aprobados los Presupuestos Generales del Estado, únicamente el Gobierno podrá presentar proyectos de ley que impliquen aumento del gasto público o disminución de los ingresos, y toda proposición o enmienda que entrañe aumento de gastos o disminución de ingresos requerirá la conformidad del Gobierno para su tramitación.»

La primera parte de ese precepto es ahora el apartado 5 del artículo 134, por la que en el conjunto el resultado ha sido la supresión de la conjunción copulativa «y».

En su génesis está, por consiguiente, claro que la sujeción de la enmienda que proponga aumento de crédito a la conformidad del Gobierno - nótese que 
en ningún caso se exige formulación constructiva- sólo rige para los proyectos de ley que el Gobierno presente «aprobados los Presupuestos Generales del Estado».

Hay, por consiguiente, razones genéticas que apoyan nuestra opinión sobre la inaplicabilidad del apartado 6 del artículo 134 al debate de los Presupuestos Generales del Estado.

Segunda. Dicho apartado menciona toda «enmienda que proponga aumento de los créditos o disminución de los ingresos presupuestarios». No tiene sentido, sin embargo, referir a la Ley de Presupuestos una enmienda que suponga la disminución de los ingresos, puesto que, como ya se vio, éstos se rigen por leyes sustantivas independientes (arts. 133 de la Constitución y 20 de la Ley General Tributaria), sin que la Ley de Presupuestos tenga con relación a ellos otro carácter que el de una simple previsión, no vinculante.

Además, el apartado 7 del artículo 134 ya dice expresamente que a través de la Ley de Presupuestos no pueden modificarse tributos, a menos que una ley sustantiva así lo prevea. Es decir, que el supuesto de una enmienda a la Ley de Presupuestos, reduciendo el tipo de gravamen de un tributo y suprimiéndolo, ya está contemplado en el párrafo aparte, y será o no posible, con independencia de la conformidad del Gobierno, según se autorice o no por una ley sustantiva.

Tercera. Digamos, por último, que la expresión créditos o ingresos «presupuestarios», empleada por el apartado 6 , sólo adquiere precisión si se refiere a cifras consignadas en los presupuestos vigentes, y no en cambio si se refiere a cifras que figuren en los presupuestos que están debatiéndose.

De lo dicho resulta:

Primero. Que en la Constitución no se prohíbe que las enmiendas al Proyecto de Ley de Presupuestos Generales del Estado propongan aumentar el gastos sin compensación, y

Segundo. Que la conformidad del Gobierno, prevista en el apartado 6, sólo es exigible para tramitar aquellas proposiciones de ley o enmiendas que, una vez aprobados los Presupuestos Generales del Estado, alteren agravándolas las cifras en ellos consignadas.

De esta suerte, España se ha incorporado a la línea seguida por la mayor parte de los países europeos, en los que se mantiene viva la tradición histórica que hace derivar al Derecho constitucional del Derecho presupuestario. Pese a ello, sigue siendo indispensable que la soberanía parlamentaria se ejercite sin móviles demagógicos, teniendo en cuenta las repercusiones financieras de cada una de sus decisiones y el imperativo de un equilibrio presupuestario. Por lo que sería muy conveniente que en los reglamentos definitivos de las Cámaras, que han de aprobarse en los próximos meses, diputados y senadores consintieran en una restricción de su constitucionalmente ilimitada capacidad.

Todo lo que antecede ha venido con ocasión de plantear una limitación a la iniciativa parlamentaria en materia presupuestaria, que habíamos llamado de carácter formal: la necesidad de plantear las enmiendas de un modo determinado.

Junto a ella, se ha hablado por la doctrina de «limitaciones funcionales», que tienen mucho más largo alcance: 
- El presupuesto, al ser reflejo de obligaciones del Estado, cifra obligaciones existentes, y la Cámara ve, en consecuencia, fuertemente limitado el objeto de su enmienda; con mucha frecuencia, la única objeción sería que, el defensor del proyecto invoca frente a las enmiendas al mismo, es que el crédito enmendado se halla ya comprometido.

- Los gastos derivan casi siempre de normas y a veces (Inglaterra y Francia) llega a constituirse un fondo consolidado, que impide la discusión de la legalidad y oportunidad de los créditos que se van a conceder.

- El examen de los ingresos se efectúa desconociendo el Parlamento las verdaderas posibilidades de exacción de las distintas figuras impositivas.

Es, por otra parte, muy frecuente que los parlamentarios aprovechen la ocasión que los presupuestos brindan -en cuanto que, a través de sus secciones, abarcan toda la acción administrativa- para proponer modificaciones que no se atienen a las cuantías consignadas en cada partida, sino que penetran en la sustancia de las instituciones. Es lo que llaman los franceses cavaliers budgetaires, prohibidos expresamente por la ordenanza orgánica en materia presupuestaria de 2 de enero de 1959, cuyo artículo 82 dice que «ningún artículo adicional y ninguna enmienda a un proyecto de ley de finanzas pueden ser presentados, salvo si tienden a suprimir o a reducir efectivamente un gasto, a crear o aumentar un ingreso o a garantizar el control de los gastos públicos».

Entre nosotros no existe norma expresa, pero puede decirse que propuestas del tipo de las referidas son incorrectas. Piénsese si no se produciría un cierto fraude aprovechando una ley que tiene unos objetivos muy precisos y que está sujeta a un procedimiento especial con plazos mucho más breves que los normales para regular a través de ella materias que debieran debatirse por el procedimiento ordinario; se incurriría, por otro lado, en infracción de las normas sobre distribución de los trabajos entre las comisiones de la Cámara, por lo menos si, como ocurre entre nosotros, se atribuye a una sola Comisión el debate presupuestario.

Otro defecto que se advierte en las enmiendas a los presupuestos es el de que se refieren a documentos que acompañan o completan a aquéllas, pero que no se identifican con ellas. Nos referimos a los anexos que reúnen los programas de inversión y a los presupuestos por programas de algunos $\mathrm{Mi}$ nisterios.

Algún órgano tiene que ser el que se encargue de estudiar las enmiendas presentadas, a la luz de los criterios que se han apuntado, para excluirlas de la tramitación. Hasta el presente, el examen lo viene haciendo la Mesa de la Comisión a la que, como órgano de dirección que es, toca decidir sobre las cuestiones de procedimiento $\mathrm{y}$, por tanto, también sobre la admisión a trámite. A veces, se producen errores de apreciación ocasionados porque no es siempre sencillo determinar si hay o no aumento. Concretamente, los problemas surgen cuando se proponen variaciones al alza en cantidades que aparecen consignadas en términos aparentemente indicativos, y no conminatorios para el Gobierno, o cuando se propone elevar la cifra por la que el Gobierno puede acudir al crédito exterior.

Es natural que las decisiones de la Mesa, que tienden a ser inapelables 
como garantía de una decisión eficaz, puedan ser revisadas en cualquier momento del debate si intervienen elementos de juicio distintos como, por ejemplo, la opinión emitida sobre el particular por los expertos del Ministerio de Hacienda en los temas presupuestarios.

Para terminar con el análisis de las enmiendas añadamos que en nuestra regulación caben tres tipos de enmiendas a la Ley de Presupuestos:

1. A la totalidad de la Ley.

2. Al conjunto de una, varias o todas las secciones.

3. A artículos o partidas específicas y determinadas.

También se puede enmendar el presupuesto-resumen de la Seguridad Social y el de los Organismos Autónomos de carácter industrial, comercial, financiero o análogo, según se deduce del art. 56.3 de la Ley General Presupuestaria según el cual «si las Cortes modificasen los Presupuestos-resumen, el Gobierno practicaría las correlativas alteraciones en el Presupuesto o en los presupuestos de las entidades u organismos afectados por la modificación».

Las enmiendas que impugnan el conjunto de una sección producen un efecto devolutivo de los Presupuestos al Gobierno, en caso de prosperar, como si se tratara de una enmienda a la totalidad. No es, sin duda, lo mismo poner en cuestión el conjunto de la política gubernativa que atacar y echar abajo la política seguida en un sector de su actividad. Desde un ángulo procedimental el resultado, es, sin embargo, idéntico, pues es impensable que el programa de acción del Gobierno para el siguiente ejercicio pueda aprobarse en esas condiciones: porque cada sección se corresponde con un órgano cuya existencia deriva de la Constitución o de la ley siendo, por ende, obligado proveer a su mantenimiento; lo lógico sería, en tan improbable hipótesis, que el Gobierno presentara otros presupuestos con una distribución de créditos ajustada a la planteada en la enmienda que hubiera prosperado.

Esta idea de práctica equiparación entre las dos series de enmiendas de referencia está reflejada, debidamente, en los Reglamentos de las Cámaras, los cuales sitúan el debate de las enmiendas «que implicasen la impugnación completa de una sección» inmediatamente después del debate de totalidad (artículo $107 \mathrm{RC}$ y $108 \mathrm{RS}$, ap. 1 y 5).

Estas enmiendas son, además, las de mayor alcance político y, en nuestra opinión, las únicas con verdadero sentido en el debate presupuestario de los Estados democráticos. Son aquéllas con ocasión de las cuales la oposición denuncia ante el electorado las quiebras o errores de la política del gobierno y presenta sus alternativas de conjunto, mientras que las de articulado son más propias de sistemas autoritarios, en los que todas las decisiones se administrativizan y no son posibles los planteamientos globales.

A riesgo de repetir lo ya dicho, pero convencido de su exactitud, conviene citar la conclusión extraída por la Unión Interparlamentaria respecto al Presupuesto: «Este constituye, en su unidad, el principal medio de acción del poder, y en este concepto debe ser juzgado por el Parlamento. La misión de las Asambleas no consiste en discutir, en su detalle, cada uno de sus aspectos 
técnicos, sino en formar un juicio político de conjunto sobre un acto fundamental, expresión de toda una política.»

Es ejemplar a este respecto, como casi siempre que tratamos de temas constitucionales, el caso británico. La reglamentación interna de la Cámara de los Comunes fija un tiempo de veintiséis días para el examen y votación del Estado de previsión de gastos; en este breve plazo es imposible un examen minucioso, de modo que el debate se eleva; adquiere un tono político. El Presupuesto es considerado ante todo como una cuestión de confianza: la mayoría descarga en el Gobierno la tarea de asegurar, en el plano financiero, el funcionamiento del Estado y de aplicar sus criterios por medio de la fijación de los gastos y de los ingresos. La oposición combate la política del Gobierno en un plano general, sin poner necesariamente en cuestión cada elemento del Presupuesto.

Este método (que trasfiere, en alguna medida, las prerrogativas parlamentarias desde el terreno de la elaboración de la Ley hacia el terreno del control de la actividad del ejecutivo) evita un peligro bien conocido en muchos Parlamentos: el de cansar a la opinión pública por la excesiva tecnicidad, duración y confusión de los debates presupuestarios y el de despegarla de un acto político esencial para el destino de una nación.

En consecuencia, nos parece muy importante que los Reglamentos definitivos de las Cámaras, al regular el procedimiento presupuestario regulen un debate de totalidad ante el Pleno de la Cámara, que puede ser un debate general sobre la política económica del Gobierno. Ello traería aparejada una gran simplificación del procedimiento en fases sucesivas, pues descargada la energía política en la primera, es de esperar que el trámite de enmiendas se pueda afrontar con más realismo.

Tenemos ya que terminar. Antes, sin embargo, debe dejarse constancia de que el Parlamento español mantiene en la materia presupuestaria competencias bastante más amplias de las que por ejemplo tiene el Parlamento francés. Allí el Gobierno somete a votación grandes masas presupuestarias, con lo cual tiene un notable poder discrecional que ejerce luego por medio de los decretos de reparto totalmente al margen del control parlamentario. Allí también el Gobierno puede plantear la cuestión de confianza sobre el presupuesto y ello ha llevado con frecuencia a su aprobación sin deliberación apenas por las Cámaras. Nada de esto es posible en España. Aquí el artículo 112 de la Constitución sólo permite plantear la cuestión de confianza ante el Congreso de los Diputados, sobre su programa o sobre una declaración de política general. Los presupuestos no encajan en estas categorías y, además, debe intervenir necesariamente el Senado en su aprobación. Tampoco existe la limitación de plazos que se conoce en Inglaterra. A los veintiséis días del procedimiento británico hay que contraponer tres meses en el Parlamento español. Es un plazo que, aunque breve, es razonable para un proyecto de ley.

Por último, queremos señalar también que los presupuestos deben ser necesariamente aprobados por el Pleno de las Cámaras sin que su aprobación pueda delegarse en la Comisión, por prohibirlo expresamente el artículo 75.3 de la Constitución. Esto no es sino una confirmación del rango solemne que, 
como señalábamos, acompaña a la aprobación de los presupuestos desde su origen.

Para terminar quisiéramos volver al punto de partida; recordar que la etapa histórica en que nos encontramos está marcada por la presencia del Estado social de Derecho, que tiene una serie de exigencias traídas de la mano del progreso y del avance técnico; que los ejecutivos que han llevado siempre la batuta de la gobernación de los asuntos del Estado han tenido que afianzar su posición como respuesta al reto de la técnica y de la complejidad de los problemas y que el Parlamento no ha tenido más remedio que transformar progresivamente su posición en el campo de las relaciones entre los poderes, transformación que la mayoría de las veces ha sido interpretada como crisis. Debe recordarse que, pese a todo, le restan funciones trascendentales:

- Ejercer la crítica de la política del Gobierno.

- Orientarla hacia ciertos objetivos.

- Constituir la representación genuina de la sociedad nacional.

- En fin, garantizar la publicidad de los actos gubernamentales de tal manera que éstos no se conviertan en «arcana imperii» de las oligarquías políticas y sus tecnocracias auxiliares.

También quisiéramos recordar siguiendo al profesor francés Georges Burdeau que el arte de la oposición, a la que tan escaso papel pretenden algunos que queda en el debate de los Presupuestos, es un arte sutil en el que los matices son a menudo más eficaces que los golpes de efecto.

\section{BIBLIOGRAFIA UTILIZADA}

García Pelayo, M.: Las transformaciones del Estado contemporáneo, Alianza Editorial, 1978.

García Pelayo, M.: Parlamentos bicamerales, Universidad de Venezuela, Ed. del Congreso de la República, Caracas, 1971.

Burdeau, G.: Traité de Sciencie Politique, tomos V y VII, Ed. L. G.D. J., 1970 y 1972.

PoulantzAs, N.: Las transformaciones actuales del Estado, en el libro La crisis del Estado, Ed. Fontanella, 1977.

Buci-Guucksman, C.: Sobre el concepto de crisis del Estado y su bistoria, en el libro La crisis del Estado, Ed. Fontanella, 1977.

LefÈbVRe, H.: De l'État, Union Général d'Éditions, 1976.

Sáinz de BujANDA, F.: Notas de Derecho financiero, Facultad de Detecho, 1968-1972.

HinTzE, O.: Historia de las formas politicas, Ed. Revista de Occidente, 1968.

LOEWENSTEIN, K.: Teoría de la Constitución, Ed. Ariel, 1970.

Mortati, C.: Istituzioni di diritto pubblico, Ed. Cedam, Padua, 1969.

Rogari, U.: Il bilancio dello stato, Ed. Cedam, Padua, 1977.

Tossi, S.: Diritto Parlamentari, Ed. Giuffrè, Milán, 1974.

Manzella: Il Parlamento, Ed. Il Mulino, 1977.

LALUMIERE, P.: Les finances publiques, Ed. Armand Colin, 1973.

Trotabas y CotTERET: Droit budgetaire, Ed. Dalloz, 1972.

RECODER DE CASSO, E.: Los presupuestos en el anteproyecto de Constitución (artículo incluido en los estudios sobre el proyecto de Constitución), Ed. CEC, 1978. 